\title{
Marketing of sheep in Sudan, profile of the market system and production: a case study of North Kordofan and Khartoum States, Sudan
}

\begin{abstract}
Sudan is one of the main exporters of sheep in African countries. Despite being on the marketing system of sheep is still undeveloped due to weakness of structural facilities such as low production technology, despised farms, market barrens, poor infrastructure and so on. This study aims to provide some insights on the marketing system of sheep in Sudan with special focus on the production sector in North Kordofan and Khartoum states in Sudan. The objectives of this study are to gain a better understanding of how the existing sheep marketing systems and to identify key constraints and potentials in the systems and to determine the marketing channels and margins. Primary data was used in this study to collect data from 103 sheep producers/traders in Elkhiwi and Elobied markets in North Kordofan and 25 producers/traders and middlemen in Elsalam in Omdurman central market in Khartoum. The results reveals that best time to selling sheep before Hajj season when the sheep begin to export to Saudi Market and other markets, the major sheep production cost items, were feed, drinking water and labor which contributing substantially to total costs $65.61 \%$ in Khartoum and 59.71\% in North Kordofan. The marketing channels were so lengthy and middlemen's margins were almost equivalent to producer's profits. The study recommends intensive research for pasture improvement; provide sheep producers/traders with improvement in production technology, reduce marketing channel and price support for the supply of fodder, water and veterinary care and waive income taxes for the farmers.
\end{abstract}

Keyword: Marketing costs; Sheep; Channel; Marketing margin; Taxes 